\title{
BIODIVERSITAS LOBSTER DI TELUK PRIGI, TRENGGALEK JAWA TIMUR
}

\author{
Arief Setyanto $^{\mathrm{a}, *}$, Siti Halimah ${ }^{\mathrm{a}}$ \\ ${ }^{a}$ Fakultas Perikanan dan Ilmu Kelautan, Universitas Brawijaya, Malang, Indonesia \\ *Koresponden penulis : asetyanto@ub.ac.id
}

\begin{abstract}
Abstrak
Studi tentang sebaran dan metode penangkapan dalam pengelolaan perikanan lobster adalah perlu dilakukan. Jenis lobster kelompok Panulirus di Indonesia khususnya di Selatan Jawa memiliki tingkat endemisitas tinggi. Perikanan lobster juga memegang peran sosial, ekonomi dan ekologi yang sangat penting. Studi ini bertujuan untuk mengidentifikasi spesies lobster di Selatan Jawa Timur khususnya di Teluk Prigi, Watulimo, Trenggalek, JawaTimur. Sampling dilakukan antara Pebruari-Juni 2018 dengan mengidentifikasi morfologi lobster hasil tangkap nelayan. Spesies lobster yang ditemukan ada lima jenis yaitu lobster pasir (Panulirus homarus), lobster mutiara (P.ornatus), lobster bambu (P. versicolor), lobster batu (P.penicillatus), lobster batik (P.longipes). Spesies dominan selama musim penangkapan lobster adalah jenis lobster pasir. Lobster ditangkap dengan tiga jenis alat tangkap yaitu: gill net, krendet dan ditangkap tanpa menggunakan alat tangkap (penyelaman). Gill net banyak menangkap jenis lobster pasir dibandingkan jenis lainnya. Krendet dan penyelaman banyak mendapatkan lobster pasir, lobster bambu, lobster mutiara dan lobster batik serta sedikit menangkap jenis lobster bambu.
\end{abstract}

Kata Kunci: gill net, krendet, lobster, sebaran, pengelolaan

\begin{abstract}
It is necessary to observe species distribution and fishing methods applied for lobster fisheries management. It is well known that Panulirus lobster in Indonesia, located in the south Sea of Java, has high endemicity. Lobster fisheries also hold a very important social, economic and ecological role. This study aims to identify lobster species in South Sea of Java, particularly in TelukPrigi, Watulimo, Trenggalek, East Java. Sampling was carried out between February-June 2018 by identifying the morphology of lobster caught by fishers. There were five species of lobster found, namely sand lobster (Panulirus homarus), pearl lobster ( $P$. ornatus), bamboo lobster (P. versicolor), rock lobster (P. penicillatus), batik lobster ( $P$. longipes). The dominant species during the lobster fishing season is a sand lobster. Lobster is caught with three types of fishing gear, namely: gill net, krendet and diving. Gill net caught more amount of sand lobster compared to caught other species. Krendet and diving got more amount of sand lobster, bamboo lobsters, pearl lobsters and batik lobsters and then collected a few amount of bamboo lobster.
\end{abstract}

Keywords: gill net, krendet, lobster, dispersal, management

\section{PENDAHULUAN}

Indonesia secara geografis dikelompokkan kedalam regional laut Asia Timur dimana memiliki spesies lobster dengan tingkat keanekaragaman dan endemisitas yang tinggi[1]. Ada 19 jenis lobster yang dikenal di dunia dalam kelompok genus Panulirus mempunyai habitat daerah tropis dan bernilai komersial cukup tinggi diantara kategori produksi perikanan yang lain [2, 3], enam spesies diantaranya: Panulirus ornatus, $P$. pennicilatus, $P$. versicolor, $P$. polyphagus, $P$. homarus and $P$. longipes ditemukan hampir di seluruh perairan Indonesia termasuk Laut Selatan Jawa. Masing-masing species mungkin mempunyai daerah penyebaran sama dan mungkin juga berbeda[4]. Dalam wilayah laut teritorial Indonesia Lautan India mencakup wilayah perairan Barat Sumatra, Selatan Jawa dan Selatan Bali dan Nusa Tenggara. 
Keenam spesies lobster tersebut dilaporkan tertangkap dan didaratkan oleh nelayan di beberapa wilayah seperti: Lombok, Nusa Tenggara Barat [5], Selatan Bali, Bali [6, 7], Pangandaran, Jawa Barat [8], sampai Aceh Barat, Aceh [9]. Sementara infromasi dari beberapa literatur yang tidak terpublikasi, keenam spesies lobster tersebut tertangkap oleh nelayan di semua kabupaten di sepanjang pantai Selatan Jawa yaitu: Jember, Pacitan, GunungKidul, Kebumen, Cilacap, and Pangandaran. Oleh sebab itu dapat dikatakan bahwa perairan Selatan Jawa Timur merupakan habitat bagi keenam spesies lobster terebut. Secara umum lobster banyak mendiami substrat yang berupa lubang-lubang, retakan batu karang, dan dasar pantai berbatu karang.Penyebaran secara vertikalnya berkisar antar tepat di bawah permukaan air sampai dengan kedalaman lebih dari 100 meter. Habitat lobster ini adalah mulai dari garis pantai hingga pada batas landas kontinen[10].

Pengelolaan perikanan di Indonesia dibagi dalam 11 Wilayah Pengelolaan Perikanan. Lobster adalah salah satu dari Sembilan kelompok sumberdaya yang menjadi indicator pengelolaan. Laut Selatan Jawa merupakan bagian dari Samudera Hindia dengan kode 573. Tiap wilayah pengelolaan mempunyai tipe biogeografi yang berbeda. Tingkat pemanfaatan sumberdaya pada masing-masing wilayah juga berbeda. Kajian tentang sebaran lobster dan metode penangkapan/eksploitasinya diperlukan untuk memonitor dan mengontrol pemanfaatan sumberdaya tersebut.

\section{METODE}

Dalam penelitian ini sampel penelitian yang digunakan merupakan hasil tangkap nelayan local pada periode waktu Februari sampai dengan Juni 2018 di Teluk Prigi, Watulimo, Trenggalek (Gambar 1).

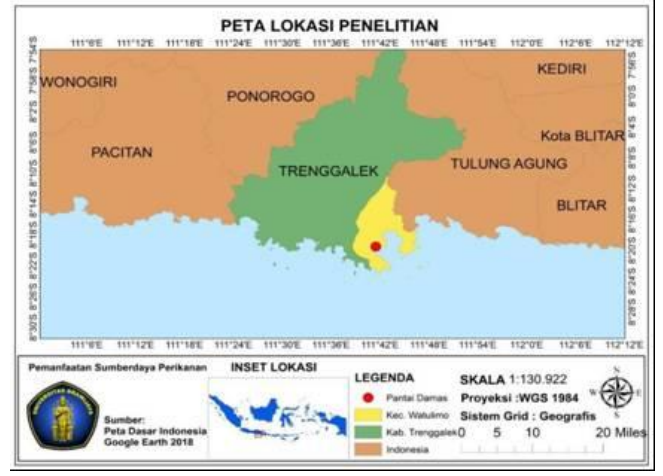

Gambar 1. Peta lokasi penelitian

Identifikasi lobsterpada penelitian ini mengacu pada buku Holthuis, L.B. 1991. dan Carpenter, K. E., dan V. H. Niem. 1998. Spesies lobster dicatat menurut bulan dan jenis alat tangkap. Alat tangkap lobster berupa gill net (Gambar 2), krendet (Gambar 3) dan menyelam (Gambar 4).

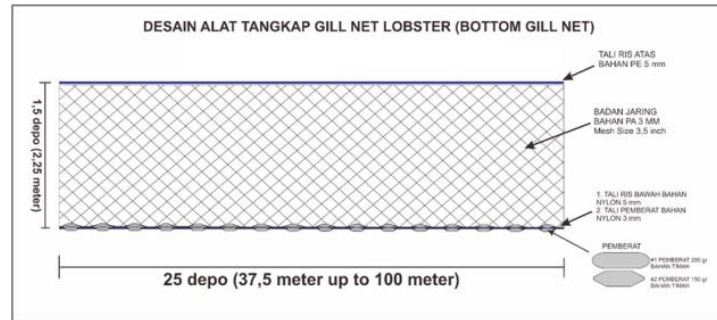

Gambar 2. Konstruksi gill net lobster

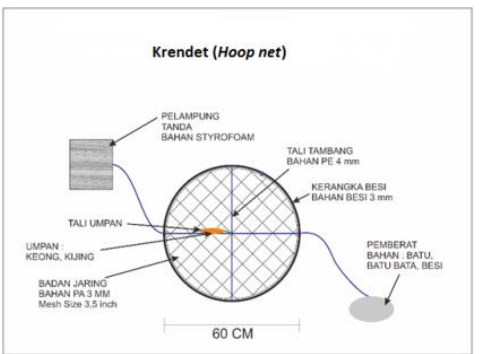

Gambar 3. Konstruksi krendet

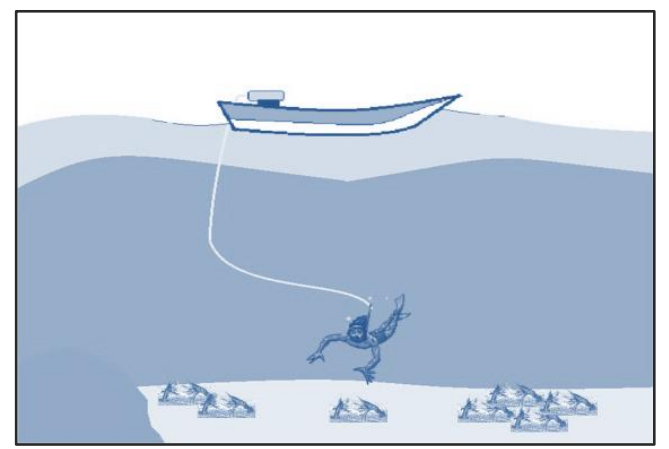

Gambar 4. Ilustrasi penangkapan lobster dengan menyelam 
Data kemudian dianalisa dengan metode analisa frekuensi Chi-square untuk mengetahui komposisi spesies pada tiap perlakuan (bulan dan alat tangkap) dengan aplikasi software MS Excel dan SPSS (Statistics Programs for Social Science).

\section{HASIL DAN PEMBAHASAN}

Ciri-ciri spesies lobster yang ditemukan berikut gambarnya adalah seperti berikut:

1) Lobster Pasir (Linnaeus, 1758)

Menurut Linnaeus (1758) dalam Carpenter dan Niem (1998b), klasifikasi Lobster pasir yaitu sebagai berikut:
Kingdom : Animalia
Phylum : Arthropoda
Class : Crustacea
Order : Decapoda
Family : Palinuridae
Genus : Panulirus
Spesies : Panulirushomarus
Nama FAO : Scalloped Spiny Lobster

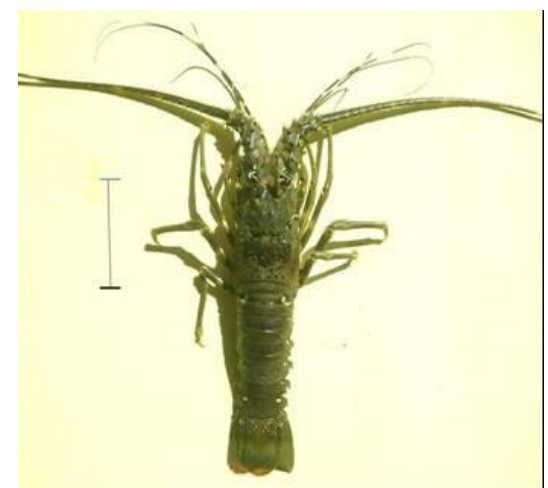

Gambar 5. Lobster Pasir (P.homarus).

2) Lobster Mutiara (Fabricius, 1798)

Menurut Fabricius (1798) dalam

Carpenter dan Niem (1998b), klasifikasi Lobster mutiara yaitu sebagai berikut:

Kingdom : Animalia

Phylum : Arthropoda

Class : Crustacea

Order : Decapoda

Family : Palinuridae

Genus : Panulirus

Spesies : Panulirusornatus

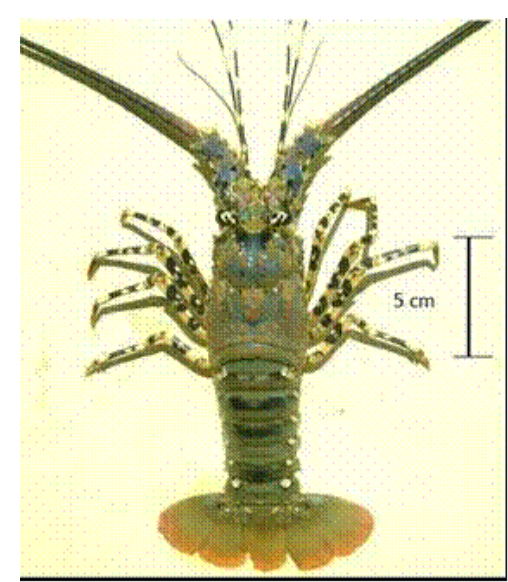

Gambar 6. Lobster mutiara (P.ornatus)

3) Lobster Bambu (Latreille, 1804)

Menurut Latreille (1804) dalam Carpenter dan Niem (1998b), klasifikasi Lobster bamboo yaitu sebagai berikut :

Kingdom : Animalia

Phylum : Arthropoda

Class : Crustacea

Order : Decapoda

Family : Palinuridae

Genus : Panulirus

Spesies : Panulirus versicolor

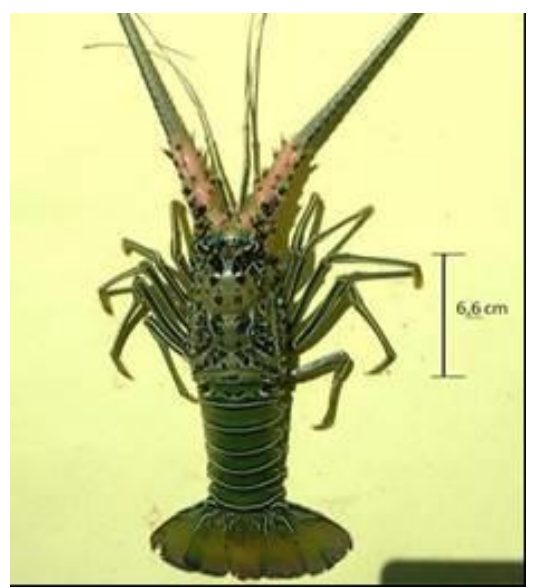

Gambar 7. Lobster bambu (P. versicolor)

4) Lobster Batu

Menurut Olivier (1791) dalam Carpenter dan Niem (1998b), klasifikasi

Kingdom : Animalia

Phylum : Arthropoda

Class : Crustacea

Order : Decapoda

Family : Palinuridae

Genus : Panulirus

Spesies : Panulirus penicillatus 


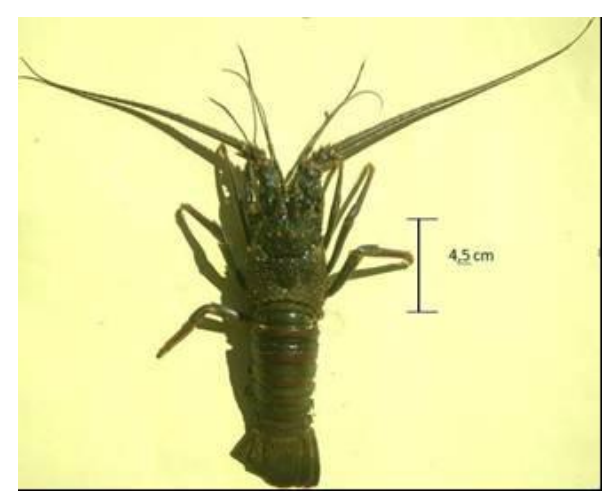

Gambar 8. Lobster Batu (P.penicillatus)

5) Lobster Batik (A Milne Edward, 1868)

Menurut A Milne Edward (1868)

dalam Carpenter dan Niem (1998b),

klasifikasi Lobster batik yaitu sebagai

berikut:

Kingdom : Animalia

Phylum : Arthropoda

Class : Crustacea

Order : Decapoda

Family : Palinuridae

Genus : Panulirus

Spesies : Panulirus longipes

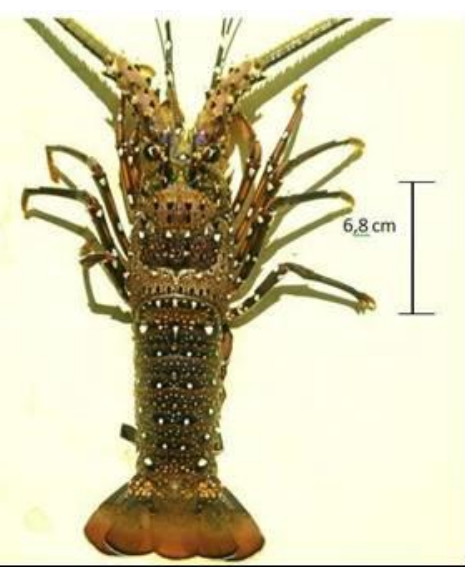

Gambar 9. Lobster batik (P. longipes)

Data jumlah individu spesies lobster yang dijadikan sampel berdasarkan waktu/bulan (Tabel 1) dan alat tangkap (Tabel 2) adalah sebagai berikut:

Tabel 1 Jumlah individu lobster pada bulan sampling.

\begin{tabular}{lrrrrl}
\hline & L.Pasir & L.Mutiara & L.Bambu & L.Batu & L.Batik \\
\hline Februari & 22 & 12 & 15 & 2 & 0 \\
Maret & 48 & 12 & 13 & 39 & 0 \\
April & 59 & 4 & 13 & 28 & 4 \\
Mei & 52 & 0 & 12 & 35 & 1 \\
Juni & 20 & 5 & 7 & 17 & 3 \\
Februari & 22 & 12 & 15 & 2 & 0 \\
\hline
\end{tabular}

Tabel 2 Jumlah individu lobster pada tiap jenis alat tangkap.

\begin{tabular}{lrrrrr}
\hline & L.Pasir & L.Mutiara & L.Bambu & L.Batu & L.Batik \\
\hline Gill net & 193 & 12 & 23 & 0 & 1 \\
Krendet & 8 & 14 & 27 & 121 & 6 \\
Menyelam & 0 & 7 & 10 & 0 & 1 \\
\hline
\end{tabular}

Uji Chi square diterapkan untuk membuktikan perbedaan komposisi jumlah individu spesies lobster pada bulan dan alat tangkap yang berbeda. Hasil uji chi-square adalah sebagai berikut:

Tabel 3. Hasil uji Chi-square komposisi spesies lobster per Bulan.

\begin{tabular}{lllllllllllll}
\hline & \multicolumn{1}{c}{ L.Pasir } & \multicolumn{1}{c}{ L.Mutiara } & L.Bambu & \multicolumn{1}{c}{ L.Batu } & \multicolumn{3}{c}{ L.Batik } \\
& Obs & Exp & Obs & Exp & Obs & Exp & Obs & Exp & Obs & Exp \\
\hline Februari & 22 & 24,23 & 12 & 3,97 & 15 & 7,23 & 2 & 14,5 & 0 & 0,9 \\
Maret & 48 & 53,21 & 12 & 8,73 & 13 & 15,88 & 39 & 32,03 & 0 & 2,11 \\
April & 59 & 51,31 & 4 & 8,42 & 13 & 15,31 & 28 & 30,89 & 4 & 2,04 \\
Mei & 52 & 47,51 & 0 & 7,8 & 12 & 14,18 & 35 & 28,60 & 1 & 1,89 \\
Juni & 20 & 24,70 & 5 & 14,0 & 7 & 7,37 & 17 & 14,873 & 0,89
\end{tabular}

Chi-square $=64,38, \mathrm{df}=16, \mathrm{p}<0,001$, Tolak $\mathrm{H}_{0}$

Keterangan :

Obs : Observed

Exp : Expected

Tabel 4. Hasil uji Chi-square komposisi spesies lobster per alat tangkap.

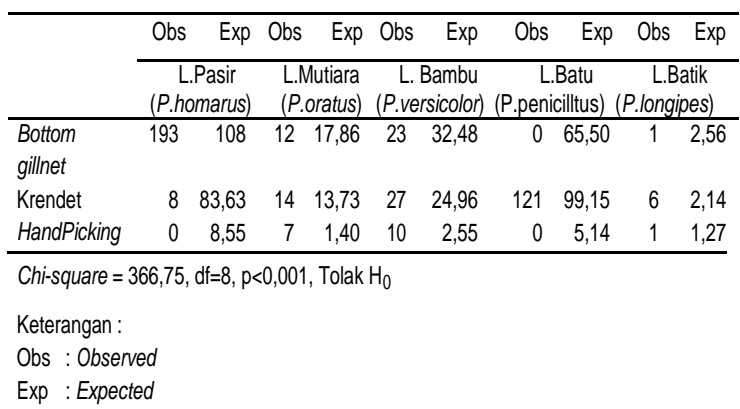

Pada hasil perhitungan metode Chisquare menunjukkan nilai sebesar 64,38 sedangkan pada Chi-square table dengan probabilitas 0,01 dan df sebesar 16 adalah 39,25, sehingga $t$ hitung lebih besar dibandingkan dengan $t$ tabel. Kesimpulan yang dapat diambil adalah tolak $\mathrm{H} 0(\mathrm{X} 2(1)=$ $64,38 ; \mathrm{p}<0,01)$ dan terima $\mathrm{H} 1$, dapat diketahui bahwa terdapat perbedaan komposisi spesies lobster yang tertangkap menurut bulan saat penelitian. 


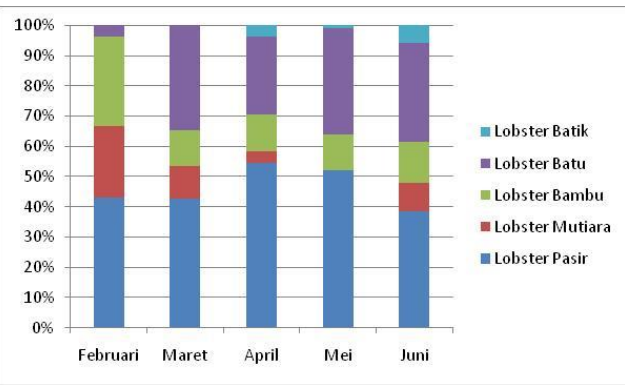

Gambar 10. Grafik komposisi lobster per Bulan

Pada data hasil tangkapan spesies berdasarkan penggunaan alat tangkap yang berbeda menunjukkan nilai 366,75 sedangkan pada Chi-square tabel dengan probabilitas 0,01 dan df sebesar 8 adalah 26,12 , sehingga disimpulkan ada perbedaan komposisi spesies lobster yang tertangkap dengan alat tangkap yang berbeda.

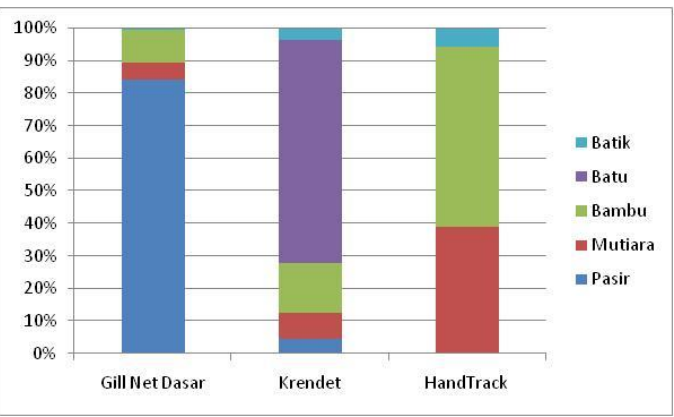

Gambar 11. Komposisi lobster per alat tangkap.

Handpicking sebenarnya bukanlah alat tangkap seperti krendet maupun jarring insang dasar, namun handpicking adalah suatu cara penangkapan yang menggunakan tangan secara langsung dan biasanya menggunakan alat bantu seperti peralatan selam. Dari penelitian ini, didapatkan hasil bahwa handpicking menghasilkan jumlah tangkapan lobster yang lebih sedikit dibandingkan dengan kedua alat tangkap lainnya, hal ini dikarenakan handpicking biasanya dilakukan oleh nelayan pada saat musim puncak penangkapan lobster yang jatuh pada bulan Oktober hingga Februari awal, sehingga cara penangkapan ini sangat jarang dilakukan di saat musim paceklik lobster. Nelayan yang menyelam untuk menangkap lobster secara langsung hanya akan menyelam atau berjalan disepanjang batuan karang dan tebing dan mengambil lobster yang terlihat. Umumnya, dengan cara penangkapan ini semua spesies lobster dapat tertangkap, namun pada penelitian ini diperoleh hasil bahwa lobster mutiara (Panulirus ornatus), lobster bambu (Panulirus versicolor) dan lobster batik (Panulirus longipes) saja yang dapat tertangkap.

Analisis mengenai komposisi lobster yang tertangkap dan alat tangkap yang digunakan pada penangkapan lobster ini dilakukan untuk melihat keadaan sumberdaya lobster yang ada di perairan Teluk Damas. Hal yang dapat disimpulkan dari hasil analisis komposisi lobster dimana Lobster pasir ( $P$. homarus) merupakan lobster yang dominan yang tertangkap pada saat penelitian atau dalam kurun waktu bulan Februari hingga Juni. Alat tangkap yang dominan digunakan oleh nelayan lobster di perairan Teluk Damas dan efektif untuk menangkap lobster pasir ini adalah bottom gillnet. Sehingga, penelitian tentang aspek biologi dan bioekonomi akan terfokus pada spesies lobster pasir ( $P$. homarus) yang tertangkap menggunakan alat tangkap bottom gillnet.

\section{KESIMPULAN}

Pengelolaan perikanan lobster di laut selatan Jawa Timur khususnya di Teluk Prigi Trenggalek semestinya menggunakan lobster pasir sebagai indikator spesies dengan alat tangkap utama gill net dan krendet. Pengelolaan perikanan lobster ini perlu dilanjutkan dengan studi tentang sebaran atau dispersal spesies lobster pada tiap fase hidup. Metode yang dipakai bisa menggunakan identifikasi spesies pada masing-masing fase hidup (larva, juvenil, dewasa) pada waktu dan tempat yang berbeda. Metode tagging atau marking dan genetic juga menarik dilakukan untuk melihat sebaran pada level yang lebih luas dan tingkat ketelitian studi yang lebih tinggi. Penelitian tentang biologi dan dinamika populasi lobster tiap spesies kemudian perlu dilakukan dengan skala waktu dan tempat yang sudah diindikasikan pada penelitian sebelumnya. Penelitian atau studi tersebut secara integral diperlukan dalam menentukan pengelolaan dengan pengaturan input dan output kontrol.

\section{UCAPAN TERIMKASIH}

Terima kasih kepada BPP FPIK UB atas support financial untuk studi ini. Dinas 
Perikanan dan Kelautan Trenggalek dan PPN Prigi beserta staf atas ijin, bantuan dan fasilitas yang diberikan selama penelitian. Masyarakat nelayan teluk Prigi (pantai Damas) atas kejujuran, keramahan dalam memberi informasi selama pengambilan data di lapang.

\section{DAFTAR PUSTAKA}

[1] J. Keesing and T. Irvine, "Coastal biodiversity in the Indian Ocean: The known, the unknown and the unknowable," Indian Journal of Marine Sciences, vol. 34, pp. 11-26, Mar 2005.

[2] L. B. Holthuis, FAO species catalogue. Marine lobsters of the world. An annotated and illustrated catalogue of species of interest to fisheries known to date. FAO Fisheries Synopsis. No. 125, Vol. 13 vol. 13. Rome: FAO, 1991.

[3] L. Garibaldi, "The FAO global capture production database: A six-decade effort to catch the trend," Marine Policy, vol. 36, pp. 760-768, 5// 2012.

[4] M. Moosa and I. Aswandy, Udang Karang (Panulirus spp.) dari Perairan Indonesia (The rock lobster (Panulirus spp.) from Indonesian waters). Jakarta: Studi Potensi Sumber Daya Hayati Ikan. Lembaga Oseanologi Nasional. Lembaga Ilmu Pengetahuan Indonesia (LIPI). 1984.

[5] W. Subani, "Studi Mengenai Pergantian Kulit Udang Barong (Spiny lobster, Panulirus spp.) Kaitannya dengan Hasil Tangkapan," Marine Fisheries Research Report, vol. 30, pp. 99-105, 1984.

[6] W. Subani, "Survay on lobster's fishing gears in south coast of Bali (Survai alat penangkapan udang barong di pantai selatan Bali)," Marine Fisheries Research Report vol. 25, pp. 37-45, 1983.

[7] W. Subani and P. Prahoro, "Status Nelayan dan Perkiraan Potensi Udang Barong (Spiny lobster) di Pantai Selatan
Bali " Journal of MArine Fisheries Research, vol. 54, pp. 9-19, 1990.

[8] A. Suman, M. Rijal, and W. Subani, "Status of spiny lobster in Pangandaran waters, West Java (Status Perikanan Udang KArang di perairan pangandaran, Jawa Barat)," Journal of MArine Fisheries Research, vol. 81, pp. 1-7, 1993.

[9] A. Suman and W. Subani, "The exploitation of spiny lobster resources in West Aceh waters (Pengusahaan Sumberdaya Udang Karang di Perairan Aceh Barat) " Journal of MArine Fisheries Research, vol. 81, pp. 84-90, 1993.

[10] R. N. Lipcius and D. B. Eggleston, "Introduction Ecology and Fishery Biology of Spiny Lobsters. In Phillips, B.F. and Kittaka, J. (eds.) Spiny Lobsters: Fisheries and Culture. Fishing News Books. London. Pp. 1-41.," ed, 2000.

[11] M. D. Spalding, H. E. Fox, B. S. Halpern, M. A. McManus, J. Molnar, G. R. Allen, et al., "Marine ecoregions of the world: A bioregionalization of coastal and shelf areas," Bioscience, vol. 57, pp. 573-583, Jul-Aug 2007. 